University of New Orleans

ScholarWorks@UNO

2001

\title{
Acclimation to Hypoxia Increases Survival Time of Zebrafish, Danio rerio, during lethal hypoxia
}

\author{
Bernard B. Rees \\ University of New Orleans, brees@uno.edu \\ F Sudradjat
}

J W. Love

Follow this and additional works at: https://scholarworks.uno.edu/biosciences_facpubs

Part of the Biology Commons

\section{Recommended Citation}

Rees, B.B., Sudradjat, F., and Love, J.W. 2001. Acclimation to hypoxia increases survival time of zebrafish, Danio rerio, during lethal hypoxia. Journal of Experimental Zoology 289: 266-272.

This Article is brought to you for free and open access by the Department of Biological Sciences at ScholarWorks@UNO. It has been accepted for inclusion in Biological Sciences Faculty Publications by an authorized administrator of ScholarWorks@UNO. For more information, please contact scholarworks@uno.edu. 


\title{
RAPID COMMUNICATIONS
}

\section{Acclimation to Hypoxia Increases Survival Time of Zebrafish, Danio rerio, During Lethal Hypoxia}

\author{
BERNARD B. REES,* FITRI A. SUDRADJAT, AND JOSEPH W. LOVE \\ Department of Biological Sciences, University of New Orleans, New Orleans, \\ Louisiana 70148
}

\begin{abstract}
Survivorship of zebrafish, Danio rerio, was measured during lethal hypoxic stress after pretreatment in water at either ambient oxygen or at a lowered, but nonlethal, level of oxygen. Acclimation to nonlethal hypoxia $\left(\mathrm{O}_{2} \cong 15\right.$ Torr; ca. $10 \%$ air-saturation) for $48 \mathrm{hr}$ significantly extended survival time during more severe hypoxia ( $p \mathrm{O}_{2} \cong 8$ Torr; ca. 5\% air-saturation) compared to survival of individuals with no prior hypoxic exposure. The magnitude of the acclimation effect depended upon the sex of the fish: hypoxia pretreatment increased the survival times of males by a factor of approximately 9 and that of females by a factor of 3 relative to controls. In addition, survival time of control and hypoxia acclimated fish depended upon when in the year experiments were conducted. Survival times were 2-3 times longer when measured in the late fall or winter compared to survival times measured during the spring or summer. These results demonstrate a direct survival benefit of short-term acclimation to hypoxia in this genetically tractable fish. The fact that the acclimation effect depended upon the sex of the fish and the season during which experiments were conducted demonstrates that other genetic and/or environmental factors affect hypoxia tolerance in this species. J. Exp. Zool. 289:266-272, 2001.

() 2001 Wiley-Liss, Inc.
\end{abstract}

When faced with low environmental oxygen concentrations (hypoxia), teleost fishes respond with a variety of behavioral, physiological, or biochemical adjustments (Van den Thillart and Van Waarde, '85; Kramer, '87; Jensen et al., '93). These responses would be predicted to increase the survival of fish during prolonged or more extreme hypoxia. Direct tests of this expectation, however, are limited in number. Shepard ('55) showed that hypoxic acclimation of juvenile eastern brook trout, Salvelinus fontinalis, increased their survival time during lethal hypoxia, and Moss and Scott ('61) noted that, in three other species, hypoxic acclimation lowered the lethal oxygen level. Kramer and Mehegan ('81) noted behavioral changes in the guppy, Poecilia reticulata, upon hypoxic acclimation, but they did not assess the effects of acclimation on survival.

Here, we used zebrafish, Danio rerio, to test the hypothesis that short-term acclimation to hypoxia increases survivorship of this species during subsequent exposure to more severe hypoxia. The experimental design we employed was analogous to that used to demonstrate inducible thermotolerance in Drosophila and other organisms (Lindquist, '86), namely, exposure of individuals to a nonlethal stress and followed by measurement of mortality during exposure to a lethal stress. We found that pretreatment of zebrafish with nonlethal hypoxia dramatically extended the survival time in lethal hypoxia. The magnitude of the response depended upon the sex of the fish and when in the year the experiments were performed. Given the genetic tractability of zebrafish (Westerfield, '93; Detrich et al., '99), this species may represent a useful model for further investigations into the genetic and environmental determinants of inducible hypoxia tolerance in fish and other organisms.

\section{MATERIALS AND METHODS Fish maintenance}

Zebrafish were obtained from a commercial pet supplier and kept in aerated, dechlorinated tap water at room temperature $\left(21-24^{\circ} \mathrm{C}\right)$ in 20 - or $40-1$ aquariums at a density of approximately 1 fish per 2 l. Fish were fed TetraMin tropical fish food once a day, and aquarium water was continuously fil-

This work was supported by National Science Foundation Grant IBN 9723050 (to B.B.R.) and by a student internship from the Freeport-McMoRAN Foundation (to F.S.).

Grant sponsor: National Science Foundation; Grant number: IBN 9723050; Grant sponsor: Freeport-McMoRAN Foundation.

*Correspondence to: Bernard B. Rees, Department of Biological Sciences, Lakefront Campus, University of New Orleans, New Orleans, LA 70148. E-mail: brees@uno.edu

Received 17 August 2000; Accepted 31 October 2000 
tered. Ammonia levels were checked periodically, and partial water changes were performed as needed. The room in which the fish were kept had windows allowing diffuse natural light. Unless otherwise indicated, the photoperiod was not controlled. Fish were held under these conditions for at least 2 weeks prior to experiments, and they were used within 3 months of purchase. Fish were not fed for $24 \mathrm{hr}$ prior to or during experiments. Preliminary tests showed that food deprivation for this period of time did not affect the survival of control or hypoxia-pretreated fish. Fish were handled in accordance with appropriate guidelines for animal care (University of New Orleans IACUC approval number 5JUN97).

\section{Experimental design}

Zebrafish were randomly assigned to control or hypoxia-pretreated groups (10-13 fish per group) and placed in 20-l aquariums. At the beginning of an experiment, filtration was discontinued and the aquariums were sealed with tight-fitting acrylic covers. Aquarium covers had two holes through which air or mixtures of nitrogen and air were introduced and vented. Over the first 2 days of an experiment, the control group was gassed with room air. The hypoxia-pretreated group received a mixture of $10 \%$ air and $90 \%$ nitrogen to achieve a $p \mathrm{O}_{2} \cong 15$ Torr (Table 1). After $48 \mathrm{hr}$, the flow of the hypoxic gas mixture was split to both aquariums for $1 \mathrm{hr}$, thereby lowering the dissolved oxygen concentration of the control aquarium. The gas mixture was then changed to 5\% air, balance nitrogen, to generate a $p \mathrm{O}_{2} \cong 8$ Torr in both aquariums for the next $48 \mathrm{hr}$. After the gas mixture was changed to $5 \%$ air, the number of dead fish was counted in control and hypoxia-pretreated groups at intervals ranging from

TABLE 1. Water quality variables measured during hypoxia pretreatment experiments ${ }^{1}$

\begin{tabular}{ccc}
\hline & \multicolumn{2}{c}{ Pretreatment } \\
\cline { 2 - 3 } & Control & Hypoxic \\
\hline$p \mathrm{O}_{2}$ during pretreatment & 146 & 15.5 \\
(Torr) & $(144-154)$ & $(14.9-16.3)$ \\
$p \mathrm{O}_{2}$ during lethal exposure & 8.1 & 8.0 \\
(Torr) & $(7.6-8.9)$ & $(7.2-8.6)$ \\
Temperature $\left({ }^{\circ} \mathrm{C}\right)$ & 22.7 & 22.7 \\
& $(21.4-23.7)$ & $(21.9-23.8)$ \\
\hline
\end{tabular}

${ }^{1}$ Values of $p \mathrm{O}_{2}$ and temperature were measured regularly during the $48 \mathrm{hr}$ pretreatment period and during the subsequent $48 \mathrm{hr}$ during which mortality was measured (test period). Mean values for these variables were calculated for each experiment based upon at least 10 measurements. Averages of these mean values for eight experiments are presented along with the ranges of the experiment means in parentheses.
15 to 60 min over the first $9 \mathrm{hr}$ and every $3-12 \mathrm{hr}$ thereafter. Death was judged by the cessation of opercular movements and the lack of response when prodded. Dead fish were removed and frozen at $-80^{\circ} \mathrm{C}$. Fish alive at the end of the $48-\mathrm{hr}$ exposure to $5 \%$ air were sacrificed by rapid immersion in liquid nitrogen and kept at $-80^{\circ} \mathrm{C}$.

All mixtures of air and nitrogen were regulated with precision flow meters (Gilmont) to achieve a total flow rate of approximately $1 \mathrm{l} \mathrm{min}^{-1}$ to each tank. Dissolved oxygen and temperature were measured with a Model 85 Handheld Meter (Yellow Springs Instruments). Approximately 50\% of the water in each aquarium was changed every $24 \mathrm{hr}$. For aquariums exposed to hypoxia, transients in the dissolved oxygen concentrations due to water changes were kept to a minimum by using water that was partially deoxygenated by bubbling with nitrogen. Under these conditions, the desired levels of hypoxia were achieved within 1$2 \mathrm{hr}$ of initiation of gassing and remained relatively stable during the course of an experiment.

Over the course of 18 months, several experimental replicates were performed following the above protocol. In other experiments, the duration of the hypoxia pretreatment or the percentage air in the hypoxic gas mixture during pretreatment was varied (see Results). Furthermore, although results are presented only from experiments done in dechlorinated tap water, equivalent results were obtained with fish maintained in deionized water containing $50 \mathrm{mg} \mathrm{l}^{-1}$ Instant Ocean and equimolar amounts of $\mathrm{NaH}_{2} \mathrm{PO}_{4}$ and $\mathrm{Na}_{2} \mathrm{HPO}_{4}(0.083 \mathrm{mmol}$ $\mathrm{l}^{-1}$ each) as $\mathrm{pH}$ buffer (Westerfield, '93).

\section{Morphometric measurements}

Fish were thawed, briefly blotted, and measured for total mass (to the nearest $\mathrm{mg}$ ) and standard length (to the nearest $0.01 \mathrm{~cm}$ ). Condition factor was calculated as (total mass $\times$ standard length ${ }^{-3}$ ) $\times 100$. Sex of the fish was determined by dissection. For females, gonad mass was determined (to the nearest $0.1 \mathrm{mg}$ ) and the gonadosomatic index (GSI) was calculated as (gonad mass $\times$ total mass $\left.^{-1}\right) \times 100$.

\section{Statistical analyses}

Analyses of variance were used to compare the water quality and fish morphometric variables among treatment groups, experimental replicates, and for the morphometric variables, between sexes. The distributions of these variables were tested against the normal distribution with one sample Komolgorov-Smirnov tests (Sokal and 
Rohlf, '81). Body masses were not normally distributed and were logarithmically transformed prior to analysis. Equality of group variances was confirmed with $F$-max tests (Sokal and Rohlf, '81). These analyses were done with SYSTAT version 8.0 (SPSS, Inc.).

Survival analysis (Dixon and Newman, '91) was used to evaluate zebrafish mortality. This statistical approach has certain advantages over the more traditional $\mathrm{LT}_{50}$ analyses: individuals that survive the lethal treatment are included as rightcensored data; the effects of covariates can be evaluated; and the results can used to predict mortality of other individuals with certain covariate values. For these analyses, the times at which individual deaths occurred (time to death; TTD) were fit to models describing the relationship between mortality and time of exposure to $p \mathrm{O}_{2} \cong 8$ Torr. Fish alive at the end of the experiments were recorded as right-censored. Survival models assumed different distributions of the TTD data (e.g., exponential, Weibull, log-normal) and included covariates of pretreatment, season, body mass, etc. The goodness of fit of the various candidate models was determined by the log-likelihood values associated with the models. For models with an equal number of parameters, the one with the greater log-likelihood value fit the data better. For models with an unequal number of parameters, Akaike's Information Criterion (AIC) was calculated as below:

$$
\begin{gathered}
\text { AIC }=-2(\log \text {-likelihood }) \\
+2(\text { number of parameters })
\end{gathered}
$$

The model with the lower AIC was judged to fit the data better (Atkinson, '80). The effects of covariates on survival time were tested by likelihood ratio tests and the results were compared against a $\chi^{2}$ distribution. Survival analyses were done using JMP 3.1 (SAS Institute, Inc.). Throughout, statistical significance was assumed at $P \leq 0.05$.

\section{RESULTS}

Preliminary experiments showed that zebrafish survive for at least 2 days in water in which the oxygen content was roughly $10 \%$ of the air-saturated value $\left(p \mathrm{O}_{2} \cong 15\right.$ Torr or $\left.0.8-0.9 \mathrm{mg} \mathrm{O}_{2} \mathrm{l}^{-1}\right)$, whereas $\geq 80 \%$ of the fish died within $12 \mathrm{hr}$ of exposure to water at $5 \%$ of the air-saturated oxygen content $\left(\mathrm{pO}_{2} \cong 8\right.$ Torr or $\left.0.4-0.5 \mathrm{mg} \mathrm{O} \mathrm{l}^{-1}\right)$. Accordingly, to evaluate the effects of hypoxia pretreatment on zebrafish mortality, groups of 10-13 fish were exposed to water having $p \mathrm{O}_{2} \cong 15$ Torr for $48 \mathrm{hr}$, followed by 48 -hr exposure to $p \mathrm{O}_{2} \cong 8$ Torr. In parallel, control groups were held for 48 hr under air-saturated conditions $\left(p \mathrm{O}_{2} \cong 146\right.$ Torr), followed by exposure to $p \mathrm{O}_{2} \cong 8$ Torr. Eight replicate experiments following this design were performed, and other than the oxygen partial pressures during the 48-hr pretreatment period, the conditions of the control and hypoxic treatments did not differ (Table 1).

Zebrafish used in these eight experiments came from 8 batches of fish purchased over the course of 18 months, for a total sample size of 178 (Table 2 ). Males were smaller (both in mass and standard length) and slimmer (lower condition factors) than females (ANOVA, $P \leq 0.05$ ). Male and female condition factor and female GSI varied significantly according to when in the year experiments were performed (ANOVA, $P \leq 0.05$ ). Compared to experiments done in the fall or winter, fish used

\begin{tabular}{|c|c|c|c|c|}
\hline & \multicolumn{2}{|c|}{ Male fish } & \multicolumn{2}{|c|}{ Female fish } \\
\hline & Nov.-Feb. & March-July & Nov.-Feb. & March-July \\
\hline \multirow[t]{2}{*}{$\operatorname{Mass}(\mathrm{g})^{*}$} & 0.368 & 0.391 & 0.517 & 0.507 \\
\hline & $(0.022)$ & $(0.029)$ & $(0.040)$ & $(0.038)$ \\
\hline \multirow[t]{2}{*}{ Standard length $(\mathrm{cm})^{*}$} & 2.81 & 2.75 & 2.98 & 2.88 \\
\hline & $(0.05)$ & $(0.05)$ & $(0.08)$ & $(0.06)$ \\
\hline \multirow[t]{2}{*}{ Condition factor* } & 1.57 & $1.78 * *$ & 1.83 & $1.94 * *$ \\
\hline & $(0.03)$ & $(0.05)$ & $(0.04)$ & $(0.03)$ \\
\hline \multirow[t]{2}{*}{ GSI (\%) } & $\mathrm{nd}^{2}$ & nd & $7.16^{3}$ & $9.01^{* *}$ \\
\hline & & & $(0.74)$ & $(0.53)$ \\
\hline$n$ & 55 & 35 & 38 & 50 \\
\hline
\end{tabular}

TABLE 2. Morphometric measurements of zebrafish used in hypoxia pretreatment experiments ${ }^{1}$

${ }^{1}$ Values are means with the standard error of the mean shown in parentheses. Two-way ANOVAs showed no effects of treatment (i.e., control or hypoxia pretreatment) or interactions between treatment and season for any variable, and treatments have been pooled within seasons.

${ }^{2}$ Male GSI values were not determined (nd).

${ }^{3}$ Female GSI was determined for 34 fish from Nov.-Feb. experiments.

*Significantly different between sexes (ANOVA, $P \leq 0.05$ ).

**Significantly different from the corresponding value measured in fish of the same sex during Nov.-Feb. (ANOVA, $P \leq 0.05$ ). 
in experiments done in the spring and summer had higher condition factors and females had higher GSI values. There were no differences in these morphological variables between control and hypoxia-pretreated fish.

Pretreatment of zebrafish at $p \mathrm{O}_{2} \cong 15$ Torr for $48 \mathrm{hr}$ consistently delayed the onset and decreased the extent of mortality when fish were subsequently exposed to $p \mathrm{O}_{2} \cong 8$ Torr (Fig. 1). Survival analysis (Dixon and Newman, '91) demonstrated that models assuming a log-normal distribution of time to death (TTD) fit the data significantly better than models incorporating exponential, Weibull or logistic distributions. The effects of hypoxia pretreatment differed among males (Fig. 1a) and females (Fig. 1b) (i.e., there was a significant interaction between treatment group and sex) and sexes were analyzed separately. Furthermore, survival times of both sexes at $p \mathrm{O}_{2} \cong 8$ Torr were greater when experiments were performed between November and February (Fig. 1, circles) than during March through July (Fig. 1, squares). For both sexes, the simplest, most explanatory survival model included the effects of pretreatment (hypoxia or control) and when the experiments were performed (November-February vs. March-July) (Table 3). Likelihood ratio tests showed that both effects were highly significant, and their inclusion in survival models significantly improved the fit of the models to the data, as judged by their lower AIC values. Although there was seasonal variation in fish morphology (Table 2), models including mass, standard length, condition factor, or female GSI as covariates proved that these variables were not significantly related to time to death and including these covariates did not significantly improve the fits of the models to the data.

The terms of the survival model from Table 3 can be used to predict the median time-to-death (MTTD) of zebrafish according to the equation:

$$
\begin{gathered}
\ln (\text { MTTD })=\mu+\left(\beta_{\mathrm{t}}\right)(\text { treatment }) \\
+\left(\beta_{\mathrm{s}}\right)(\text { season })+(\sigma)(W),
\end{gathered}
$$

where $\mu=$ model intercept, $\beta_{t}=$ pretreatment effect (letting control pretreatment $=0$, hypoxia pretreatment $=1$ ), $\beta_{\mathrm{s}}=$ season effect (November-February experiments $=0$, March-July experiments $=1), \sigma$ = model scale parameter, $W=50$ th percentile of the standardized distribution assumed for the error (0 for the log-normal distribution).

Calculated MTTD values for male and female zebrafish are present in Table 4 . These values
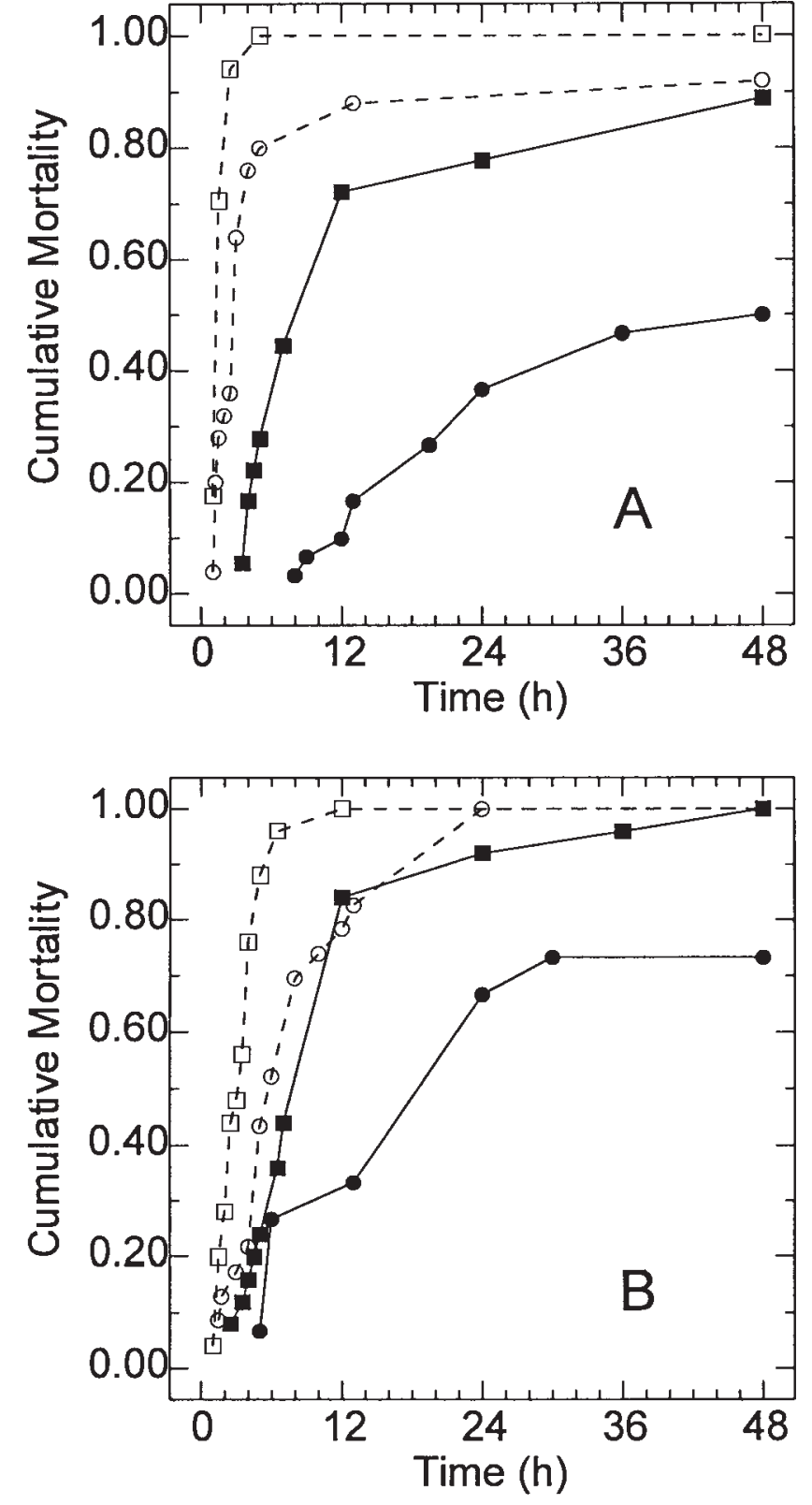

Fig. 1. Mortality at lethal hypoxia $\left(\mathrm{pO}_{2} \cong 8\right.$ Torr) of male (A) and female (B) zebrafish after $48 \mathrm{hr}$ normoxic $\left(p \mathrm{O}_{2} \cong 146\right.$ Torr; open symbols) or hypoxic ( $p \mathrm{O}_{2} \cong 15$ Torr; closed symbols) pretreatment. The abscissa represents the time of exposure to $p \mathrm{O}_{2} \cong 8$ Torr (i.e., it does not include the 48-hr pretreatment.) Cumulative mortality (ordinate) was calculated as the number of fish dead at a particular time divided by the total number for a given treatment when replicate experiments were pooled from the months of Nov.-Feb. (circles) or March-July (squares). There was no mortality during the pretreatment period for either controls or hypoxia-pretreated fish.

demonstrate that hypoxia pretreatment increases survival time by a factor of 9 for males and 3 for females. Both control and hypoxia-pretreated fish survive between 2 and 3 times longer when mea- 
TABLE 3. Summary of survival analyses

\begin{tabular}{lrrrr}
\hline Parameter & Estimate & SE & $\chi^{2 \text { a }}$ & $P$ \\
\hline A. Males $^{\mathrm{b}}$ & & & & \\
$\quad$ Intercept $(\mu)$ & 1.460 & 0.173 & & \\
$\quad$ Treatment effect $\left(\beta_{\mathrm{t}}\right)$ & 2.249 & 0.212 & 73.2 & $<0.0001$ \\
$\quad$ Season effect $\left(\beta_{\mathrm{s}}\right)$ & -1.078 & 0.215 & 22.7 & $<0.0001$ \\
$\quad$ Scale $(\sigma)$ & 0.968 & 0.085 & & \\
B. Females & & & & \\
$\quad$ Intercept $(\mu)$ & 1.918 & 0.138 & & \\
Treatment effect $\left(\beta_{\mathrm{t}}\right)$ & 1.121 & 0.163 & 38.2 & $<0.0001$ \\
$\quad$ Season effect $\left(\beta_{\mathrm{s}}\right)$ & -0.799 & 0.164 & 21.3 & $<0.0001$ \\
$\quad$ Scale $(\sigma)$ & 0.753 & 0.059 & & \\
\hline
\end{tabular}

${ }^{\mathrm{a}} \chi^{2}$ values are from likelihood-ratio tests of the effect of the covariates on time-to-death and are associated with the corresponding probabilities based upon 1 degree of freedom each.

${ }^{b}$ There was a significant interaction between sex and treatment on time to mortality, and consequently males and females were analyzed separately. The log-likelihood value for the complete model for males was -115 . The log-likelihood value for the complete model for females was -100 .

sured in the late fall or winter relative to spring or summer.

It was possible that the seasonal effect on survival times was explained, in part, by differences in photoperiod at the different times of year. Therefore, in one experiment, a batch of fish obtained in June were held under a winter-like photoperiod (10 hr light:14 hr dark) prior to and during experimentation (a total of 4 weeks). Survival times at $p \mathrm{O}_{2} \cong 8$ Torr after control and hypoxia pretreatment ( $48 \mathrm{hr}$ at $p \mathrm{O}_{2} \cong 15$ Torr) were in the same range as those measured in other experiments performed between March and July (data not shown). This result suggests that the seasonal effect was not due to differences in photoperiod during laboratory maintenance.

In separate experiments, zebrafish pretreated for 12 or $24 \mathrm{hr}$ at $p \mathrm{O}_{2} \cong 15$ Torr had rates of mortality during exposure to lethal hypoxia that were not different from controls. After $36 \mathrm{hr}$ at $p \mathrm{O}_{2} \cong$ 15 Torr, however, mortality at $p \mathrm{O}_{2} \cong 8$ Torr was reduced to the same level as observed with $48-\mathrm{hr}$ hypoxic pretreatment (data not shown). In another series of experiments, $48-\mathrm{hr}$ pretreatment of

TABLE 4. Calculated median times to death (MTTD) for zebrafish with and without hypoxia pretreatment ${ }^{1}$

\begin{tabular}{lccc}
\hline Season & Pretreatment & $\begin{array}{c}\text { Male } \\
\text { MTTD (hr) }\end{array}$ & $\begin{array}{c}\text { Female } \\
\text { MTTD (hr) }\end{array}$ \\
\hline Nov.-Feb. & Control & 4.3 & 6.8 \\
Nov-Feb. & Hypoxia & 40.8 & 20.9 \\
March-July & Control & 1.5 & 3.1 \\
March-July & Hypoxia & 13.9 & 9.4 \\
\hline
\end{tabular}

${ }^{1}$ Median times to death were calculated as stated in the text. zebrafish in water having $p \mathrm{O}_{2}$ from 25 to 40 Torr afforded only modest reductions in mortality during lethal exposures compared to normoxic controls (data not shown). On the basis of these results, it appears that $36 \mathrm{hr}$ at $p \mathrm{O}_{2} \cong 15$ Torr are the minimum conditions necessary to result in an increased tolerance to $p \mathrm{O}_{2} \cong 8$ Torr (at $22-23^{\circ} \mathrm{C}$ ). Pretreatments longer than $48 \mathrm{hr}$ were not tested.

\section{DISCUSSION}

We have demonstrated that short-term exposure of zebrafish, $D$. rerio, to nonlethal hypoxia dramatically increased their survival time when exposed to further reductions in oxygen concentration. Similarly, Shepard ('55) showed that acclimation to hypoxia of juvenile eastern brook trout, Salvelinus fontinalis, increased the survival time during lethal hypoxia between 3- and 10-fold. Shepard ('55) noted, however, that the acclimation effect required several days $\left(4-10\right.$ days at $9^{\circ} \mathrm{C}$ ), and effects were noted even when fish were acclimated to relatively high levels of oxygen (e.g., $70 \%$ of the air-saturated concentration). The differences between our study and that of Shepard ('55) in the conditions that elicit an acclimation response may be related to different habitats of these two species (temperate vs. tropical) or developmental stages studied (juvenile vs. adult). Despite those differences, the general conclusion is the same. Acclimation to hypoxia results in a significant survival benefit at lower levels of oxygen.

While our experiments do not address the mechanism of acclimation to hypoxia, it is likely that acclimation resulted in a variety of adjustments, ranging from behavioral to biochemical, each contributing to the observed increase in hypoxia tolerance. For example, zebrafish that were hypoxia pretreated were less active than controls. A reduction in activity, coupled with reduced metabolic demands, during the acclimation period may have provided an advantage when the oxygen was further lowered. Metabolic rate reduction, primarily due to decreased activity, has been demonstrated in other fish under hypoxia (Dalla Via et al., '94). Other hallmark responses of teleost fishes to hypoxia include increased ventilation rates, hematocrit, and hemoglobin oxygen affinity (Jensen et al., '93), responses that would improve the capacity of acclimated individuals to extract oxygen from their environment. In this regard, Shepard ('55) reported that the increase in survival after acclimation to hypoxia in eastern brook trout was correlated with an increased capacity for oxygen uptake. Changes at the biochemical level, e.g., an 
increased reliance upon metabolic pathways of energy production that do not require oxygen, may also have occurred during acclimation to hypoxia (Van den Thillart and Van Waarde, '85). Greaney et al. ('80) noted that acclimation of the mummichog, Fundulus heteroclitus, to hypoxia led to increased activities of the glycolytic enzymes glucose phosphate isomerase and lactate dehydrogenase in liver tissue.

That the response to hypoxia was dependent upon the sex of zebrafish was unexpected. The sex effect was such that, in the control groups, mortality was more rapid among males than females, and after hypoxia pretreatment, the converse was true. The causes of this effect, which were not explained by differences in body size or condition between sexes, are unknown. Perhaps males have a greater capacity to suppress metabolism during hypoxia since the metabolic costs of gonad tissue are likely to be lower in males, or they have a greater capacity to increase oxygen extraction or anaerobic metabolism during hypoxic acclimation.

The fact that time of the year affected survival of zebrafish during hypoxia was similarly surprising. This effect could not be explained by differences in the conditions of laboratory maintenance (i.e., temperature, dissolved oxygen, photoperiod). Zebrafish used in this study, however, were obtained from commercial suppliers who generally raise their fish in outdoor enclosures. It is possible there were seasonal differences in nutritional or reproductive status among batches of fish that persisted during laboratory maintenance and affected hypoxia tolerance. This suggestion is supported by the observation that the condition factor (mass relative to length) differed between seasons for both sexes, as did the female GSI. Both sexes were heavier relative to their length and females had larger ovaries during the spring and summer months, suggesting that reproductive investment was greater during these months than during winter. When included in survival models, however, neither condition factor nor GSI explained the variation in mortality times as well as the post hoc variable "season." Reasons for this are twofold: first, while there was significant variation in condition factor and GSI between seasons, these variables did not correlate well with survival time within a season; second, it is likely that other unknown environmental or genetic differences contributed to the season effect.

Because of their facile laboratory maintenance, short generation times and well-described genet- ics (Westerfield, '93; Detrich et al., '99), zebrafish may provide a useful model for future experiments into the genetic and environmental bases of hypoxia tolerance. For example, hypoxia-inducible factor 1 (HIF-1) has been implicated in coordinating several molecular events during hypoxia in mammalian tissues (Semenza, '99). It would be interesting to ascertain whether transgenic zebrafish expressing mutant forms of HIF- $1 \alpha$ or its dimerization partner, the aryl hydrocarbon receptor nuclear translocator (ARNT), both recently cloned in fish (Pollenz et al., '96; Soitamo et al., '99), display altered hypoxia tolerance. Furthermore, mutagenesis screens, which have been so successful in the study of zebrafish development (Fishman, '99), could be applied to the study of aspects of their physiology that might influence hypoxia tolerance (cf. Warren and Fishman, '98). Quantitative genetics could be employed to determine the inheritance of morphological, behavioral and physiological traits that correlate with hypoxia tolerance (Falconer, '81), and laboratory selection experiments could be used to probe the evolution of these traits (Garland and Carter, '94; Gibbs, '99). Such approaches could provide insight into the determinants of hypoxia tolerance in this fish and other organisms.

\section{ACKNOWLEDGMENT}

We thank numerous colleagues for helpful suggestions on statistical analyses and earlier versions of the manuscript.

\section{LITERATURE CITED}

Atkinson AC. 1980. A note on the generalized information criterion for choice of a model. Biometrika 67:413-418.

Dalla Via J, Van den Thillart G, Cattani O, deZwaan A. 1994. Influence of long-term hypoxia exposure on the energy metabolism of Solea solea. II. Intermediary metabolism in blood, liver and muscle. Marine Ecol Prog Ser 111:17-27.

Detrich HW, Westerfield M, Zon L. 1999. Overview of the zebrafish system. Methods Cell Biol 59:3-10.

Dixon PM, Newman MC. 1991. Analyzing toxicity data using statistical models for time-to-death: an introduction. In: Newman MC, McIntosh AW, editors. Metal ecotoxicology, concepts and applications. Chelsea, MI: Lewis Publishers, Inc. p 207-242.

Falconer DS. 1981. Introduction to quantitative genetics. London: Longman.

Fishman MC. 1999. Zebrafish genetics: the enigma of arrival. Proc Natl Acad Sci USA 96:10554-10556.

Garland T, Carter PA. 1994. Evolutionary physiology. Annu Rev Physiol 56:579-621.

Gibbs AG. 1999. Laboratory selection for the comparative physiologist. J Exp Biol 202:2709-2718.

Greaney GS, Place AR, Cashon RE, Smith G, Powers DA. 1980. Time course of changes in enzyme activities and blood respiratory properties of killifish during long-term acclimation to hypoxia. Physiol Zool 53:136-144. 


\section{B.B. REES ET AL.}

Jensen FB, Nikinmaa M, Weber RE. 1993. Environmental perturbations of oxygen transport in teleost fishes: causes, consequences and compensations. In: Rankin JC, Jensen FB, editors. Fish Ecophysiology. London: Chapman and Hall. p 161-179.

Kramer DL. 1987. Dissolved oxygen and fish behavior. Environ Biol Fish 18:81-92.

Kramer DL, Mehegan JP. 1981. Aquatic surface respiration, an adaptive response to hypoxia in the guppy, Poecilia reticulata (Pisces, Poeciliidae). Environ Biol Fish 6:299-313.

Lindquist S. 1986. The heat-shock response. Annu Rev Biochem 55:1151-1191.

Moss DD, Scott DC. 1961. Dissolved-oxygen requirements of three species of fish. Trans Am Soc Fish 90:377-393.

Pollenz RS, Sullivan HR, Holmes J, Necela B, Peterson RE. 1996. Isolation and expression of cDNAs from rainbow trout (Oncorhynchus mykiss) that encode two novel basic helixloop-helix/PER-ARNT-SIM (bHLH/PAS) proteins with distinct functions in the presence of the aryl hydrocarbon receptor. J Biol Chem 271:30886-30896.
Semenza, GL. 1999. Regulation of mammalian $\mathrm{O}_{2}$ homeostasis by hypoxia-inducible factor 1 . Annu Rev Cell Dev Biol 15:551-578.

Shepard MP. 1955. Resistance and tolerance of young speckled trout (Salvelinus fontinalis) to oxygen lack, with special reference to low oxygen acclimation. J Fish Res Bd Canada 12:387-446.

Soitamo AJ, Rabergh C, Gassman M, Sistonen L, Nikinmaa M. 1999. Characterization of hypoxia inducible factor $1 \alpha$ from rainbow trout (Oncorhynchus mykiss). Comp Biochem Physiol 124A(Suppl):S116.

Sokal RR, Rohlf FJ. 1981. Biometry. New York: W.H. Freeman.

Van den Thillart G, Van Waarde J. 1985. Teleosts in hypoxia: aspects of anaerobic metabolism. Mol Physiol 8:393-409.

Warren KS, Fishman MC. 1998. "Physiological genomics": mutant screens in zebrafish. Am J Physiol 275 (Heart Circ Physiol 44):H1-H7.

Westerfield M. 1993. The zebrafish book. Eugene, OR: University of Oregon Press. 